\title{
Journal of Psychohopharmacology
}

\section{Vigabatrin and Tiagabine Might have Antipanic Properties \\ P. Zwanzger and R. Rupprecht \\ J Psychopharmacol 2004 18: 440 \\ DOI: $10.1177 / 026988110401800319$}

The online version of this article can be found at:

http://jop.sagepub.com/content/18/3/440

\author{
Published by: \\ (SAGE \\ http://www.sagepublications.com
}

On behalf of:

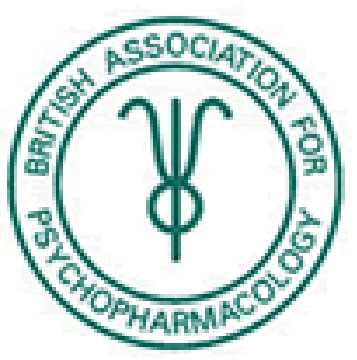

British Association for Psychopharmacology

Additional services and information for Journal of Psychopharmacology can be found at:

Email Alerts: http://jop.sagepub.com/cgi/alerts

Subscriptions: http://jop.sagepub.com/subscriptions

Reprints: http://www.sagepub.com/journalsReprints.nav

Permissions: http://www.sagepub.com/journalsPermissions.nav

Citations: http://jop.sagepub.com/content/18/3/440.refs.html

>> Version of Record - Sep 6, 2004

What is This? 


\title{
Vigabatrin and tiagabine might have antipanic properties
}

\author{
Journal of Psychopharmacology \\ 18(3) (2004) 440 \\ (C) 2004 British Association \\ for Psychopharmacology \\ ISSN 0269-8811 \\ SAGE Publications Ltd, \\ London, Thousand Oaks, \\ CA and New Delhi \\ 10.1177/0269881104044590
}

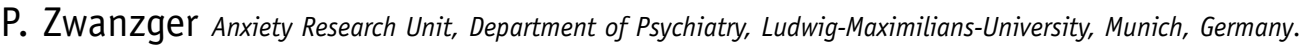

\author{
R. Rupprecht Anxiety Research Unit, Department of Psychiatry, Ludwig-Maximilians-University, Munich, Germany.
}

In their recent perspectives paper, Ashton and Young (2003) discuss the important issue of the therapeutic potential of selective GABAergic treatment in affective disorders. The authors review data available on the new antiepileptic drugs gabapentin, vigabatrin, tiagabine, pregabalin, topiramate, lamotrigene, amongst others. They conclude that this new generation of GABA enhancers might have a therapeutic potential in some affective disorders and chronic pain. The beneficial effects for anxiety disorders remain to be seen. Regarding the side-effects of these compounds, the question of the development of tolerance and dependency would be especially important (Ashton and Young, 2003).

This prompts us to share some of our recent experiences in the treatment of panic and anxiety using vigabatrin and tiagabine.

Initial studies by our group on the effects of vigabatrin and tiagabine on experimentally-induced panic with cholecystokinintetrapeptide (CCK-4) in healthy volunteers showed a significant reduction of panic scores after 1 week of treatment with both compounds (Zwanzger et al., 2001c; Zwanzger et al., 2003). Based on these results, which suggested putative antipanic properties in patients with anxiety disorders, we investigated the effects of vigabatrin and tiagabine in patients suffering from panic disorder, with and without agoraphobia (DSM-IV), in two small open-label trials. Treatment with vigabatrin led to a marked reduction reduction of anxiety on the HAMA-scale after 2 weeks and a improvement of agoraphobia measured with the Bandelow Agoraphobia Scale. Remission was obtained after 4 weeks of treatment. A follow-up investigation showed that these effects could be maintained in the following 6 months (Zwanzger et al., 2001a). In a similar trial, treatment with tiagabine also led to a marked improvement of panic and agoraphobia in panic disorder patients. In two out of four patients, remission was obtained after 4 weeks (Zwanzger et al., 2001b).

All patients were treated in the anxiety clinic and outpatient clinic of the department of psychiatry. After the trial, follow-up treatment was provided for all participants. During this period, patients were seen continuously at intervals of 2-4 weeks for approximately 1 year. Within this period, medication was tapered off slowly over 4-6 weeks in most subjects. Psychopathology, possible side-effects and the development of tolerance and withdrawal symptoms were monitored by experienced psychiatrists. Apart from mild dizziness or vertigo, no major side-effects were observed in the acute phase of the study. These symptoms most commonly were reported during the first few days of treatment and after dose increase in the patients treated with tiagabine. After treatment discontinuation, no withdrawal symptoms such as sweating, tremor, increased blood pressure or heart rate were observed. Similarly, there were no reports of a sudden increase of anxiety or reoccurrence of panic attacks.

In conclusion, these initial clinical experiences in patients with panic disorder provide further evidence that GABAergic compounds might constitute an alternative treatment approach in patients with anxiety disorders, and support the relevance of selective GABAergic compounds in the treatment of affective disorders, as suggested by Ashton and Young (2003). Furthermore, clinical observations after long-term treatment with both compounds do not suggest a risk for the development of tolerance and withdrawal after treatment discontinuation.

\section{References}

Ashton H, Young A H (2003) GABA-ergic drugs: exit stage left, enter stage right. J Psychopharmacol 17: 174-178

Zwanzger P, Baghai T, Boerner R J, Möller H J, Rupprecht R (2001a) Anxiolytic effects of vigabatrin in panic disorder. J Clin Psychopharmacol 21: 539-540

Zwanzger P, Baghai T, Schüle C, Minov C, Padberg F, Möller H J, Rupprecht R (2001b) Tiagabine improves panic and agoraphobia in panic disorder patients. J Clin Psychiatry 62: 656-657

Zwanzger P, Baghai T, Schüle C, Ströhle A, Padberg F, Kathmann N, Schwarz M, Möller H J, Rupprecht R (2001c) Vigabatrin decreases cholecystokinin tetrapeptide (CCK-4) induced panic in healthy volunteers. Neuropsychopharmacology 25: 699-703

Zwanzger P, Eser D, Padberg F, Baghai T C, Schule C, Roetzer F, Ella R, Moller H J, Rupprecht R (2003) Effects of tiagabine on cholecystokinintetrapeptide (CCK-4) induced anxiety in healthy volunteers. Depress Anxiety 18: 140-143 